\title{
Assembling SnO Nanosheets into Microhydrang- eas: Gas Phase Synthesis and Their Optical Property
}

\author{
Zhenglin Zhang ${ }^{1,2}$, Jing Wang ${ }^{1}, \quad$ Zhou $\mathrm{Yu}^{1}, \quad$ Fengyu $\mathrm{Qu}^{1}$, Xiang $\mathrm{Wu}^{1,2, *}$
}

(Received 25 September 2012; accepted 4 November 2012; published online 10 November 2012.)

\begin{abstract}
Large scale $\mathrm{SnO}$ microhydrangeas are obtained successfully through thermally evaporating of $\mathrm{SnO}_{2}$ powder wrapped by a filter paper at $1050^{\circ} \mathrm{C}$ and using gold coated $\mathrm{Si}$ wafer as the substrate. The as-obtained $\mathrm{SnO}$ microhydrangeas are consisted of many thin nanosheets with the thicknesses of 30-60 nm and the diameters of 500-600 nm. A vapor-liquid-solid (VLS) growth mechanism for the as-synthesized SnO microhydrangeas was proposed based on experimental results. Photoluminescence spectrum (PL) shows that there is a strong sharp ultraviolet emission peak at $390 \mathrm{~nm}$, revealing that these three-dimensional $\mathrm{SnO}$ microhydrangeas may have potential applications in optoelectronic fields.
\end{abstract}

Keywords: SnO; microhydrangeas; Photoluminescence; VLS

Citation: Zhenglin Zhang, Jing Wang, Zhou Yu, Fengyu Qu and Xiang Wu, "Assembling SnO Nanosheets into Microhydrangeas: Gas Phase Synthesis and Their Optical Property", Nano-Micro Lett. 4 (4), 215-219 (2012). http://dx.doi.org/10.3786/nml.v4i4.p215-219

To design rationally the desired nanostructures with the controlled size and shape is a key step toward the future nanotechnological applications. $\mathrm{SnO}$ and $\mathrm{SnO}_{2}$ are two important wide band gap semiconductors. Tin dioxide $\left(\mathrm{SnO}_{2}, E_{g}=3.62 \mathrm{eV}\right.$, at $\left.300 \mathrm{~K}\right)$ has been widely studied due to its promising applications in gas sensors [1-3], solar cells [4], optical devices [5-6], lithium ion batteries [7-8], and photocatalysts [9-11]. In contrast, the investigation of $\mathrm{SnO}$ materials has fallen behind, perhaps because it decomposes easily at elevated temperature and the divalent tin ion can be oxidized to the tetravalent one. However, as is known, $\mathrm{SnO}$ is technologically important as a p-type semiconductor, which is a key functional material that has been widely studied for various potential applications [12]. In the past few decades, many $\mathrm{SnO}$ crystals with uniform nanostructures are obtained including sheets [13], wires [14], diskettes [15], and nanoribbons [16]. Those materials have been widely explored for rechargeable lithium batteries [17-18], and storage of solar energy [19]. However, synthesis of hydrangealike $\mathrm{SnO}$ structure with thin nanosheet assemblies is rarely reported [20].

In the present work, we present a simply Thermally vapor deposition approach for the controlled growth of $\mathrm{SnO}$ microhydrangeas. Morphologies and optical property of the as-synthesized products are investigated by different characterization techniques. The growth mechanism was also proposed.

$\mathrm{SnO}$ microhydrangeas were synthesized using a facile chemical vapor deposition (CVD) method in a conventional horizontal tube furnace (inner diameter $40 \mathrm{~mm}$, length $70 \mathrm{~cm}$, see Fig. 1(c)). The Si substrates were covered with a layer of $\mathrm{Au}$ film of about $5 \mathrm{~nm}$. First, the substrates were immersed into acetone and ethanol in succession, washed ultrasonically for 15 minutes and

\footnotetext{
${ }^{1}$ Key Laboratory for Photonic and Electronic Bandgap Materials, Ministry of Education and College of Chemistry and Chemical Engineering, Harbin Normal University, Harbin, 150025, P. R. China

${ }^{2}$ Key Laboratory of Colloid and Interface Chemistry, Ministry of Education and College of Chemistry and Chemical Engineering, Shandong University, Jinan, 250100, Shandong, P. R. China.

*Corresponding author. E-mail: wuxiang05@gmail.com
} 

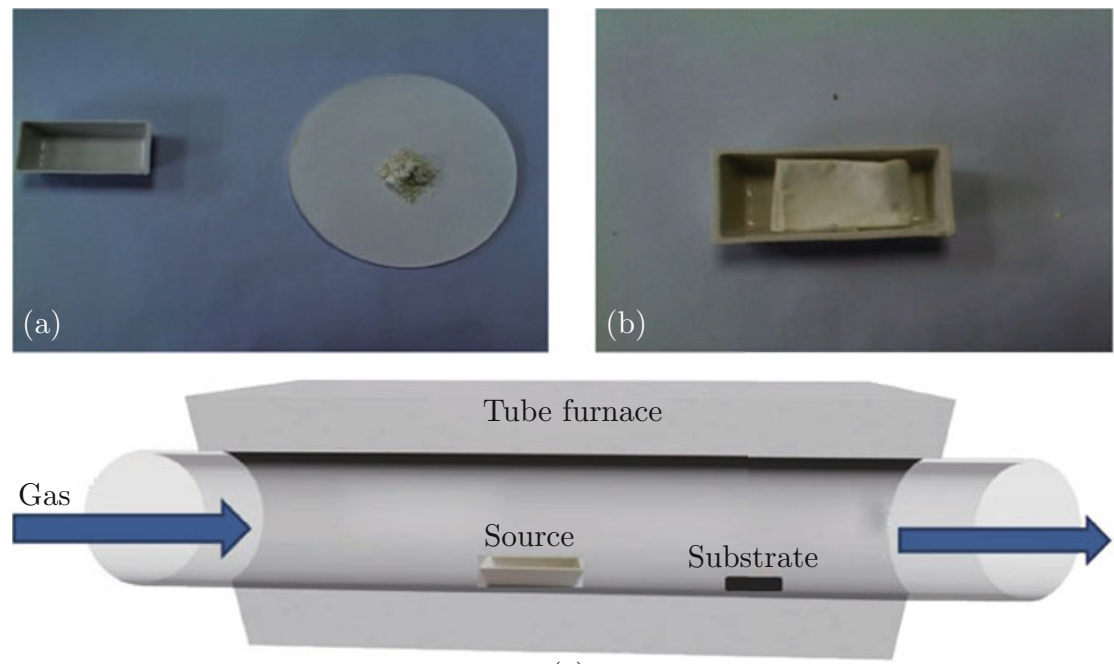

(c)

Fig. 1 (a-b) Digital photographs of the filter paper wrapped $\mathrm{SnO}_{2}$ power and the boat. (c) Schematic illustration of experimental setup to synthesize the $\mathrm{SnO}$ nanostructures.
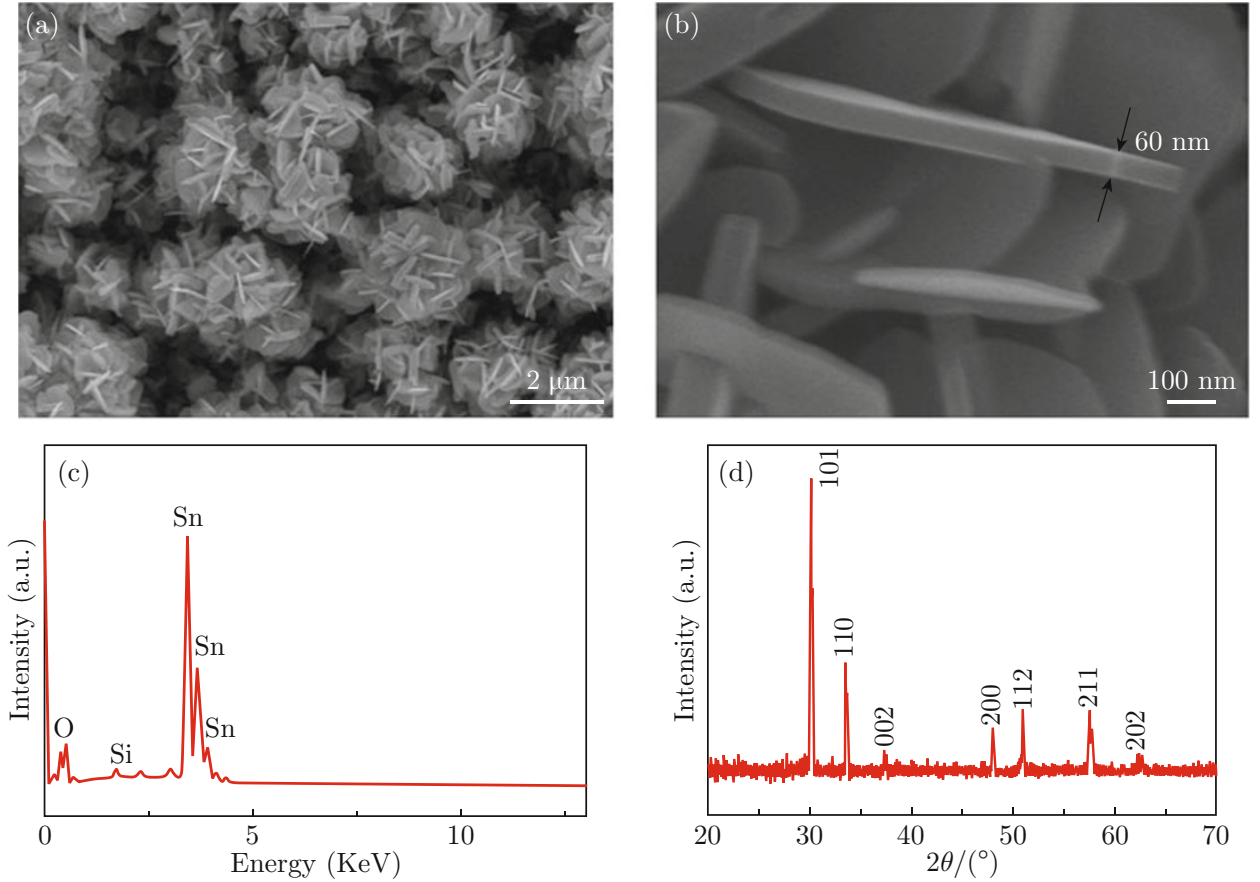

Fig. 2 Morphology of the as-synthesized SnO microhydrangeas. (a-b) SEM images at different magnifications. (c) Energydispersive spectrum (EDS) recorded from $\mathrm{SnO}$ microhydrangeas. (d) XRD pattern of the as-obtained SnO nanostructures.

rinsed with deionized water, then dried by a drier. The substrates were placed downstream, which are $21 \mathrm{~cm}$ away from the source material. $1 \mathrm{~g} \mathrm{SnO}_{2}(99.98 \% \mathrm{pu}-$ rity) was tightly wrapped by a filter paper (Fig. 1(a)(b)), and was put into an alumina boat. Then, the boat was taken into the horizontal tube furnace. Subsequently, the whole system was evacuated for $30 \mathrm{~min}$ by a vacuum pump. The temperature was rapidly increased from room temperature up to $1050^{\circ} \mathrm{C}$ and kept $1 \mathrm{~h}$ at this temperature. Carrier of argon flowed into the tube at the rate of $100 \mathrm{sccm}$, and the pressure was kept at 10 Torr. Finally, the furnace was cooled down room temperature. The substrates were taken out from the tube. The as-synthesized products were characterized by X-ray diffraction instrument (Rigaku Dmax-rB, $\mathrm{CuK} \alpha$ radiation, $\lambda=0.1542 \mathrm{~nm}, 40 \mathrm{KV}, 100 \mathrm{~mA}$ ), scanning electron microscope (SEM, Hitachi-4800), microRaman spectrometer (HR800) and Photoluminescence spectrum (HORIBA JY-Fluoro Max 4).

Morphology of the as-synthesized product is characterized firstly by SEM. A typical low magnification SEM image is shown in Fig. 2(a), revealing large quan- 
tities of hydrangealike structures with average diameters of 2-3 $\mu \mathrm{m}$. Figure 2(b) shows a high magnification SEM image of the as-synthesized products, which are consisted of some nanosheets with smooth surfaces with the average thicknesses of $60 \mathrm{~nm}$. The energy dispersive X-ray spectrum (EDS) of the as-synthesized nanostructure is shown in Fig. 2(c), EDS quantitative analysis gives an average $\mathrm{Sn} / \mathrm{O}$ ratio of 40.88:59.12 within the accuracy of the technique. The peaks for $\mathrm{Sn}$ and $\mathrm{O}$ are originated from the source material. Si element is from the substrate. Figure 2d shows XRD pattern of the assynthesized products. All of the diffraction peaks can be indexed to a tetragonal $\mathrm{SnO}$ structure (JCPDS Card No.06-0395), with lattice constants of $a=3.796 \AA$ and $c=4.816 \AA$. The sharp and strong diffraction peaks indicate that the as-synthesized $\mathrm{SnO}$ hydrangealike nanostructures are highly crystalline.

Raman spectrograph is utilized to further study the microstructure of the as-synthesized product. Figure 3 shows a Raman scattering spectrum of the asobtained hydrangealike microstructure at room temperature. Four major vibration peaks located at 80, 107, 138 and $207 \mathrm{~cm}^{-1}$ can be found. The Raman spectrum exhibits two Raman modes at $113 \mathrm{~cm}^{-1}\left(E_{1 g}\right)$ and $211 \mathrm{~cm}^{-1}\left(A_{1 g}\right)$ in previous report [21]. Besides these typical Raman modes, the other two peaks at 80 and $138 \mathrm{~cm}^{-1}$ are assigned as $B_{1 g}$ mode and $E_{2 g}$ mode, respectively. These peaks further confirm that the $\mathrm{SnO}$ nanostructures possess the characteristics of the tetragonal $\mathrm{SnO}$ structure [22].

To investigate the growth mechanism of the asobtained $\mathrm{SnO}$ microhydrangeas, temperature dependent experiments are conducted. In Fig. 4(a), only a small quantity of nanosheets were observed for $1 \mathrm{~min}$. Adding time to $30 \mathrm{~min}$ (in Fig. 4(b)), it was found that large quantities of nanosheets with a relative smooth surfaces deposited on the substrate. However, it is not assembled to microhydrangeas. When increasing to 1 $\mathrm{h}$ at the temperature, many hydrangealike structures appeared, as shown in Fig. 4(c).

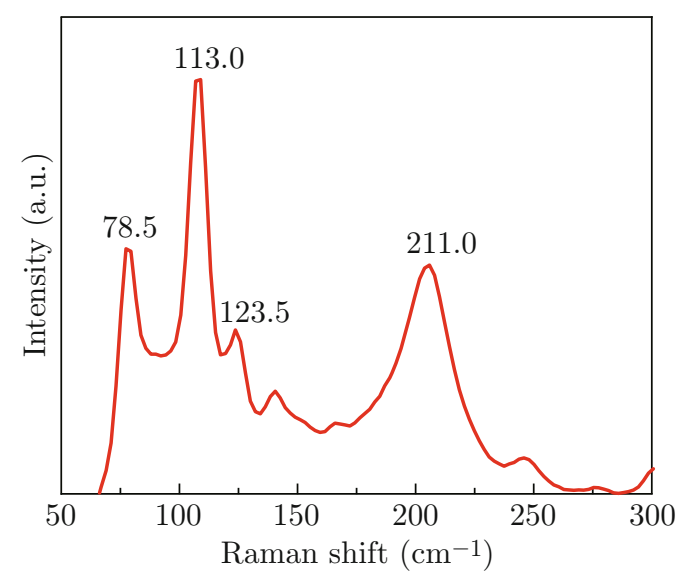

Fig. 3 Raman spectrum of the as-synthesized product.

Experiment results indicated that growth of the assynthesized product can be explained by a vapor-liquidsolid (VLS) mechanism. Figure 5 shows a growth schematic drawing of the $\mathrm{SnO}$ microhydrangeas. In the experiment, we suggest that the filter paper (main ingredient is cellulose $\left.\left(\mathrm{C}_{6} \mathrm{H}_{10} \mathrm{O}_{5}\right)_{n}\right)$ will be a direct reacting substance at the begin of the reaction. In situ carbon is obtained by heating the paper to more than
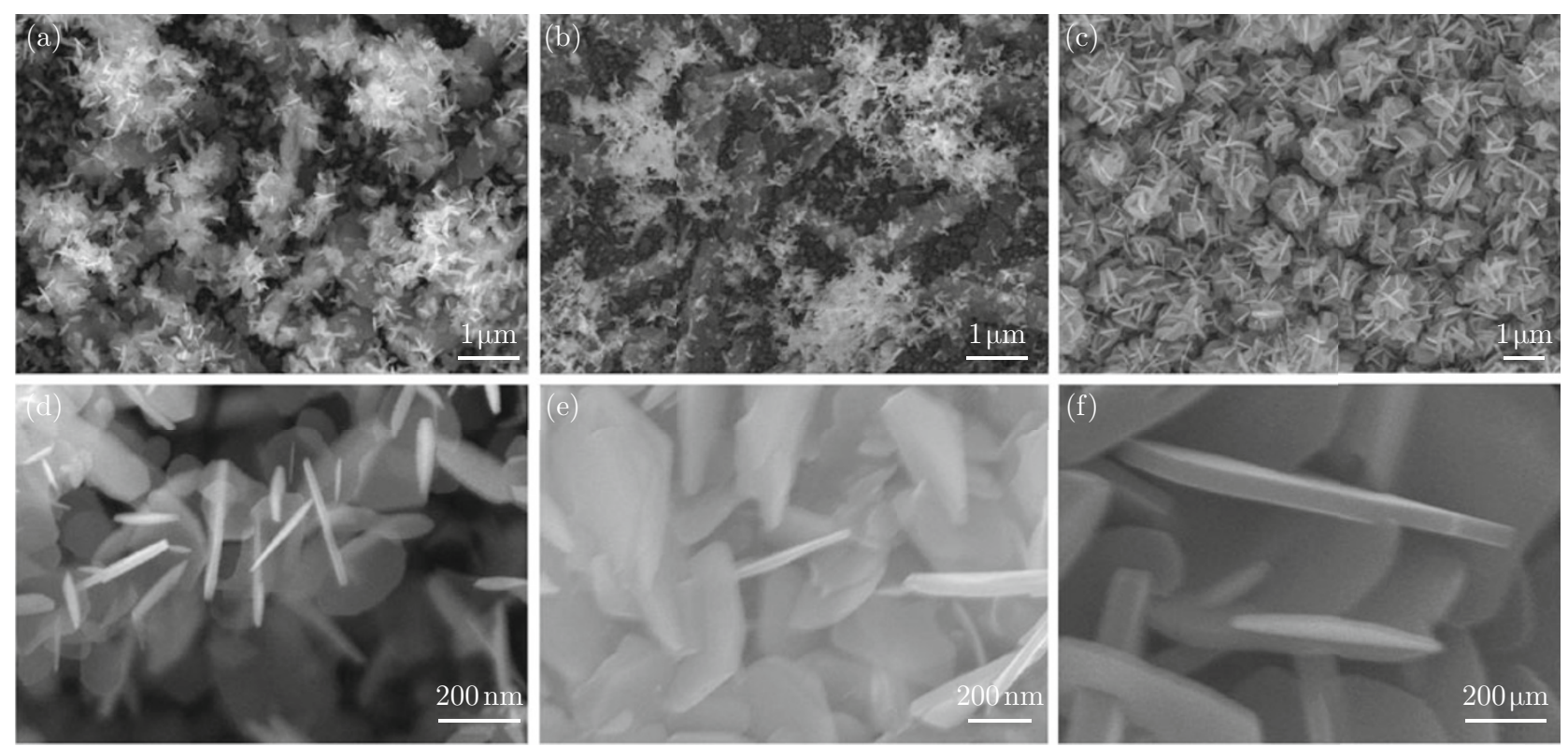

Fig. 4 SEM images of the $\mathrm{SnO}$ nanostructures by using different reaction time for $1050^{\circ} \mathrm{C}$ : (a, d) $1 \mathrm{~min},(\mathrm{~b}, \mathrm{e}) 30 \mathrm{~min},(\mathrm{c}$, f) $1 \mathrm{~h}$. 


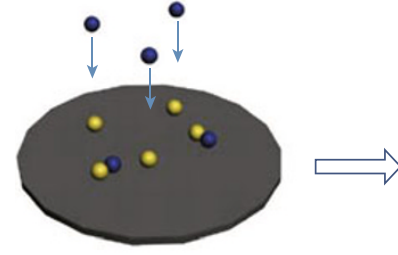

(I)

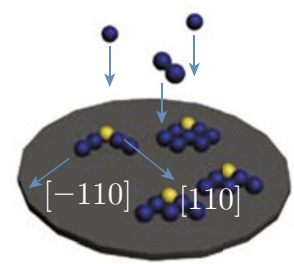

(II)

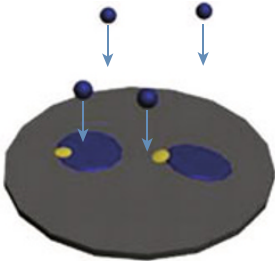

(III)

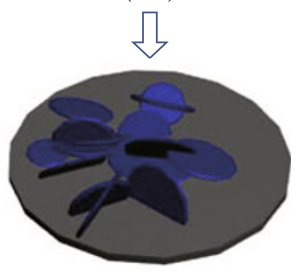

(IV)

Fig. 5 Growth Schematic drawing of the as-synthesized SnO nanostructures: (I) Metallic tin droplets dissolve with Au nanoparticles. (II) SnO nuclei grows along the [110] and [-110] crystal directions. (III) Nanosheets form (IV) a mass of SnO nanosheets form with reaction proceeds. (V) the nanosheets assemble into microhydrangeas.

$150^{\circ} \mathrm{C}$, and the carbon has more exceptional reduction ability than pure graphite or other carbon material.

Next, as the temperature is elevated, the following chemical reactions occur:

$$
\begin{aligned}
& \mathrm{SnO}_{2}(\mathrm{~s})+\mathrm{C}(\mathrm{s}) \longrightarrow \mathrm{SnO}(\mathrm{g})+\mathrm{CO}(\mathrm{g}) \\
& \mathrm{SnO}(\mathrm{g})+\mathrm{CO}(\mathrm{g}) \longrightarrow \mathrm{Sn}(\mathrm{l})+\mathrm{CO}_{2}(\mathrm{~g})
\end{aligned}
$$

In reaction $1, \mathrm{SnO}$ vapors and $\mathrm{CO}$ gas are generated in high temperature region of the tube furnace. The reaction products were then transported downstream by the Ar gas flow, where reaction 2 shall occurs. Sn vapor can be dissolved in Au nanoparticle catalyst to form Sn-Au alloy. When solubility of the $\mathrm{Sn}$ vapor in the $\mathrm{Au}$ nanoparticle reaches supersaturated, Sn can overflow from the Au nanoparticle catalyst and react with residual oxygen in the closed system to form $\mathrm{SnO}$ nuclei at the catalyst interface [23, 24]. The tetragonal phase $\mathrm{SnO}$ structure are preferentially oriented along the [110] and [-110] growth directions. With the reaction progress, $\mathrm{SnO}$ nuclei can assemble into $\mathrm{SnO}$ nanosheets and further microhydrangeas. No $\mathrm{Au}$ particles have been found on tops of the obtained nanosheets, which probably have been evaporated during the growth of the $\mathrm{SnO}$ nanosheets, this explanation is consisted with $\mathrm{ZnO}$ and $\mathrm{MgB}_{2}$ nanohelices [25, 26].

Room temperature photoluminescence (PL) spectrum of the obtained $\mathrm{SnO}$ microstructures are measured with UV light excitation at $300 \mathrm{~nm}$. Figure 6 shows single and strong emission spectra at $390 \mathrm{~nm}(3.18 \mathrm{eV})$, no obvious other emission peak can be found. $\mathrm{SnO}$ with the tetragonal structure is a p-type semiconductor with a wide optical band gap of 2.7-3.4 eV. So, the ultraviolet PL peak at $390 \mathrm{~nm}(3.18 \mathrm{eV})$ is possibly attributed to the band edge emission of $\mathrm{SnO}[20]$. In literature, $\mathrm{SnO}$ thin films exhibited a broad dominant peak near $396 \mathrm{~nm}$ $(3.13 \mathrm{eV})[27]$. It suggests the quantum-confinement ef- fect in $\mathrm{SnO}$ nanostructures induces a blue-shift of the absorption band [14].

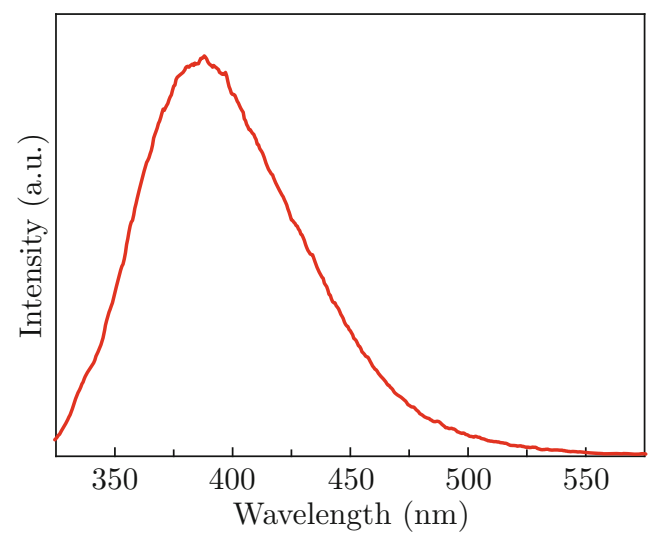

Fig. 6 Photoluminescence spectrum of the as-obtained $\mathrm{SnO}$ nanostructures.

In summary, large quantities of $\mathrm{SnO}$ microhydrangeas through assembling nanosheets are successfully synthesized though a CVD method. A possible growth mechanism based VLS growth for the assynthesized product is proposed. Photoluminescence spectrum measurement showed a strong emission peak at $390 \mathrm{~nm}$, which may be ascribed to band edge emission, and expected to be the promising candidate in optoelectronics micro/nanodevices.

\section{Acknowledgements}

This work was sponsored by China Postdoctoral Foundation (2012M511016), Special Fund of Postdoctoral Innovation Projects in Shandong Province (201201007), Postdoctoral Initiation Foundation of Shandong University and the Foundation for Key Project of Ministry of Education, China (No. 211046) 


\section{References}

[1] C. N. Xu, J. Tamaki, N. Miura and N. Yamazoe, Sens. Actuators B 3, 147 (1991). http://dx.doi.org/10. 1016/0925-4005(91) 80207-Z

[2] Y. L. Wang, X. C. Jiang and Y. N. Xia, J. Am. Chem. Soc. 125, 16176 (2003). http://dx.doi.org/10.1021/ ja037743f

[3] A. Kolmakov, D. O. Klenov, Y. Lilach, S. Stemmer and M. Moskovits, Nano Lett. 5, 667 (2005). http:// dx.doi.org/10.1021/nl050082v

[4] F. G. Fagan and V. R. Amarakoon, Am. Ceram. Soc. Bull. 72, 119 (1993).

[5] Y. T. Han, X. Wu, G. Z. Shen, B. Dierre, L. H. Gong, F.Y. Qu, Y. Bando, T. Sekiguchi, F. Fabbri, and D. Golberg, J. Phys. Chem. C 114, 8235 (2010). http:// dx.doi.org/10.1021/jp100942m

[6] Q. H. Wang, D. W. Wang and T. M. Wang, NanoMicro Lett. 3, 34 (2011). http://dx.doi.org/10. 3786/nml . v3i1.p34-42

[7] Y. Wang, F. Su, J. Y. Lee and X. S. Zhao, Chem. Mater. 18, 1347 (2006). http://dx.doi.org/10.1021/ cm052219。

[8] C. J. Kim, M. J. Noh, M. S. Choi, J. Cho and B. W. Park, Chem. Mater. 17, 3297 (2005). http://dx.doi. org/10.1021/cm048003o

[9] B. X. Jia, W. N. Jia, Y. L. Ma, X. Wu and F. Y, Qu, Sci. Adv. Mater. 4, 702 (2012). http://dx.doi.org/ 10.1166/sam. 2012.1341

[10] H. T. Huang, S. Q. Tian, J. Xu, Z. Xie, D. W. Zeng, D. Chen and G. Z. Shen, Nanotechnology 23, 105502 (2012). http://dx.doi.org/10.1088/0957-4484/23/ 10/105502

[11] Y. H. Han, X. Wu, Y. L. Ma, L. H. Gong, F. Y. Qu and H. J. Fan, Cryst. Eng. Comm. 13, 3506 (2011). http://dx.doi.org/10.1039/c1ce05171g

[12] Y. Ogo, H. Hiramatsu, K. Nomura, H. Yanagi, T. Kamiya, M. Hirano and H. Hosono, Appl. Phys. Lett. 93, 032113 (2008). http://dx.doi.org/10.1063/1. 2964197

[13] K. Sakaushi, Y. Oaki, H.Uchiyama, E. Hosono, H. S. Zhou and H. Imai, Small 6, 776 (2010). http://dx. doi.org/10.1002/smll. 200902207

[14] K. Sakaushi, Y. Oaki, H. Uchiyama, E. Hosono, H. S. Zhou and H. Imai, Nanoscale 2, 2424 (2010). http:// dx.doi.org/10.1039/c0nr00370k
[15] Z. R. Dai, Z. W. Pan and Z. L. Wang, J. Am. Chem. Soc. 124, 8673 (2002). http://dx.doi.org/10.1021/ ja026262d

[16] Z. L. Wang and Z. W. Pan, Adv. Mater. 14, 1029 (2002). http://dx.doi.org/10.1002/15214095 (20020805) 14: 15<1029: : AID-ADMA1029>3. 0 . CO;2-3

[17] D. Aurbach, A. Nimberger, B. Markovsky, E. Levi, E. Sominski and A. Gedanken, Chem. Mater. 14, 4155 (2002). http://dx.doi.org/10.1021/cm021137m

[18] J. J. Ning, T. Jiang, K. K. Men, Q. Q. Dai, D. M. Li, Y. J. Wei, B. B. Liu, G. Chen, B. Zou and G. T. Zou, J. Phys. Chem. C 113, 14140 (2009). http://dx.doi. org/10.1021/jp905668p

[19] Z. J. Wang, S. C. Qu, X. B. Zeng, J. P. Liu, F. R. Tan, Y. Bi and Z. G. Wang, Acta Mater. 58, 4950 (2010). http://dx.doi.org/10.1016/ j.actamat. 2010.05.022

[20] B. Liu, J. H. Ma, H. Zhao, Y. Chen and H. Q. Yang, Appl. Phys. A 107, 437 (2012). http://dx.doi.org/ 10.1007/s00339-012-6760-6

[21] J. Geurts, S. Rau, W. Richter and F. J. Schmitte, Thin Solid Films 121, 217 (1984). http://dx.doi.org/10. 1016/0040-6090 (84)90303-1

[22] Y. Q. Guo, R. Q. Tan, X. Li, J. H. Zhao, Z. L. Luo, C. Gao and W. J. Song. Cryst. Eng. Comm. 13, 5677 (2011). http://dx.doi.org/10.1039/c0ce00949k

[23] J. Q. Hu, X. L. Ma, N. G. Shang, Z. Y. Xie, N. B. Wong, C. S. Lee and S. T. Lee, J. Phys. Chem. B 106, 3823 (2002). http://dx.doi.org/10.1021/jp0125552

[24] J. X. Wang, D. F. Liu, X. Q. Yan, H. J. Yuan, L. J. Ci, Z. P. Zhou, Y. Gao, L. Song, L. F. Liu, W. Y. Zhou, G. Wang and S. S. Xie, Solid State Commun. 130, 89 (2004). http://dx.doi.org/10.1016/j.ssc. 2004.01 .003

[25] X. Wu, W. Cai and F. Y. Qu, Chin. Phys. B 18, 1669 (2009). http://dx.doi.org/10.1088/1674-1056/18/ 4/065

[26] S. Y. Bae, J. Lee, H. Jung, J. Park and J. Ahn, J. Am. Chem. Soc. 127, 10802 (2005). http://dx.doi. org/10.1021/ja0534102

[27] T. W. Kim, D. U.Lee and Y. S.Yoon, J. Appl. Phys. 88, 3759 (2000). http://dx.doi.org/10.1063/1.1288021 